\author{
PATRICIA DÍAZ CAYEROS
}

INSTITUTO DE INVESTIGACIONES ESTÉTICAS, UNAM

\title{
Una carta de examen para obtener el título de maestro del carpintero poblano Pedro M uñoz ${ }^{\mathrm{I}}$
}

L 6 de agosto De I72I, un hombre de mediano cuerpo, ojos pardos, cabello corto negro con entradas de calva y un lunar sobre la ceja izquierda obtuvo el título de maestro carpintero en el ramo de ebanistería. Su carta de examen indica que dos días antes se le había otorgado otro título en el ramo de carpintería de lo blanco. ${ }^{2}$ D espués de evaluar su capacidad e indicar que el aspirante había pasado satisfactoriamente las pruebas, las autoridades de los gremios de carpintería y albañilería, así como las del ayuntamiento de Puebla, le autorizaron la contratación tanto de estructuras arquitectónicas ("carpintería de fuera") como de mobiliario ("carpintería

I. Agradezco a la licenciada Lucero Álvarez C astro, directora del Archivo M unicipal de Puebla, así como a la licenciada Aurelia H ernández la gran ayuda y atenciones que me brindaron durante mis consultas al acervo, así como el permiso otorgado para fotografiar y reproducir las imágenes que aquí se presentan. Este breve estudio forma parte de la investigación que actualmente realizo para mi tesis de doctorado en historia del arte en la unAm y se ha beneficiado de las generosas recomendaciones de la doctora Clara Bargellini y la maestra Elena Estrada de Gerlero.

2. A diferencia del examen para ebanista, en el examen para carpintero de lo blanco se le pidió que hiciera y trazara una puerta de chaflán y una prensa y que examinara los cartabones. (Archivo M unicipal de Puebla, Expedientes (serie 3 ), volumen 220, f. 153 .) Agradezco a la doctora $M$ ontserrat $\mathrm{G}$ alí el que me hiciera notar que la carta del examen en carpintería de lo blanco también se ha conservado. 
DOI: http://dx.doi.org/10.22201/iie.18703062e.2002.81.2127

152

PATRICIA DÍAZ CAYEROS

de tienda"). ${ }^{3}$ La evaluación en ambos ramos se llevó a cabo en presencia del alcalde del gremio y de tres veedores examinadores, peritos en las áreas de carpintería de lo blanco, ebanistería, carrocería, al bañilería y cantería. ${ }^{4}$ La firma de cada uno de ellos aparece en una de las pruebas encomendadas al aspirante y que todavía se conserva: un trazo de una "puerta de capilla de escritorio" que se anexó a la carta de examen. Es decir, la representación de una decoración de tipo arquitectónico para la zona frontal y central de un hipotético escritorio. ${ }^{5}$ En el documento escrito se hace un recuento del examen que - como era costumbre - fue tanto práctico como teórico. La carta de examen explica que, además de responder bien a las preguntas y de trazar la puerta de capilla de escritorio antes mencionada, trazó un bufete, una basa y una cornisa, así como un lazo en un ochavo. ${ }^{6}$ Por la escasez de este tipo de

3. Tanto en las ordenanzas para los carpinteros de Sevilla (editadas por primera vez en 1527 y por segunda en 1632) como en las de Puebla (de 1570), se distingue a los carpinteros "de tienda" (básicamente orientados hacia la fabricación de mobiliario) de aquellos capaces de realizar obras "de fuera de la tienda" (como lo era la carpintería de armar). Este segundo grupo tenía subdivisiones y todas ellas incluían actividades que demandaban un mayor grado de complejidad que la fabricación de obras de ebanistería. En el lugar más elevado se encontraban aquellos carpinteros capaces de examinarse en "cosas que tocan a la geometría". Así, el "geométrico" era un carpintero capaz de trazar y decorar armaduras de gran complejidad, como "una cuadra de media naranja de lazo lefe". Es decir, una cubierta para una bóveda semiesférica decorada con una rueda de lazo de diez. En un nivel que requería una inferior habilidad estaban aquel los carpinteros capaces de hacer y decorar armaduras con lazos. Finalmente, estaban aqueIlos que sólo conocían el arte de la fabricación de techumbres 0 armaduras. Cfr. O rdenanças de Sevilla, que por su original, son aora nuevamente impressas, Sevilla, Andrés G rande, i632 (ed. facsimilar con introducción de V. Pérez Escolano y F. Villanueva Sandino, Sevilla, O ficina Técnica de Arquitectura e Ingeniería, 1975) y Patricia Díaz Cayeros, "Las ordenanzas de los carpinteros y alarifes de Puebla", en M ontserrat Galí (coord.), El mundo de las catedrales novohispanas, Puebla, ICSH-BUAP, 2002.

4. Como en Puebla - a diferencia de lo que sucedía en la ciudad de M éxico- el gremio de carpinteros compartía ordenanzas con el de albañiles, no resulta extraño que uno de los veedores perteneciera al oficio de al bañilería.

5. V éase lo referente a "escritorios arquitectónicos" en M aría Paz Aguiló, El mueble en España, XVI-XVII, M adrid, csic-Antiqvaria, I993, pp. I05-I07.

6. Bufete: mesa grande o mediana y portátil. Por lo regular se hacía de madera o piedra, más o menos preciosa, y constaba de una tabla o dos juntas sostenidas en pies de la misma u otra materia. Se usaba para estudiar, escribir o comer. Basa: el asiento que guarnece y en que estriba y se afirma una columna, estatua, etc. 0 bien el cuerpo inferior de la columna y el pedestal (Real Academia Española, Diccionario de la lengua castellana, M adrid, Imprenta de Francisco del H ierro, I726). Respecto al "lazo en un ochavo", no se dan detalles del tipo de lazo 
I. Pedro M uñoz, trazo de una puerta de capilla de escritorio que acompaña su examen para obtener el título de maestro carpintero, i72I. Archivo M unicipal de Puebla, Expedientes (serie 3 ), volumen 220 , f. I54V. Foto: Patricia Díaz Cayeros.

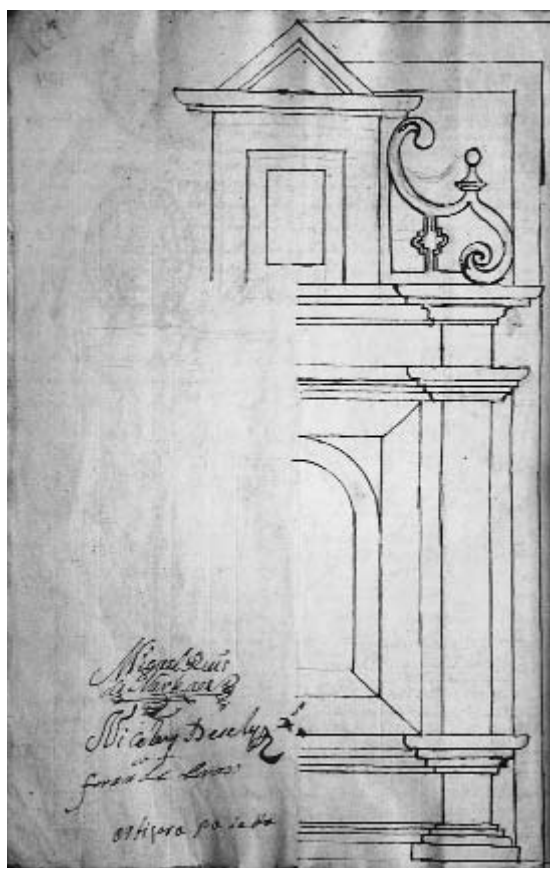

material gráfico, el hecho de que la carta conserve una de las trazas realizadas durante el examen proporciona un gran valor al documento que resguarda el Archivo M unicipal de Puebla y que hasta ahora había permanecido inédito. La importancia, sin embargo, aumenta al constatar que el nuevo maestro respondía al nombre de Pedro M uñoz.

\section{¿Q uién era Pedro M uñoz?}

De espaldas al altar mayor de la Catedral de Puebla, de frente a la reja que impide el acceso al coro, la vista acaso penetra el espacio hasta detenerse sobre las dos cartelas localizadas en ambos extremos de la sillería. Al centro de ellas, una inscripción casi del todo invisible desde el interior del coro se le re-

que Pedro M uñoz trazó circunscribiéndose a una forma ochavada. Probablemente se trató del tipo de diseños utilizados para decorar armaduras en la carpintería de armar. 
vela al visitante que se detiene en el umbral del espacio. D el lado de la epístola, se lee el mismo nombre de quien en agosto de i72r era examinado en la ciudad de Puebla con la finalidad de obtener el título de maestro carpintero: "Comenzó esta obra el maestro Pedro M uñoz el año de i7ı"', mientras que del lado del evangelio la frase culmina proporcionando las fechas exactas en que la obra fue realizada: "a 24 de agosto y la acabó a 24 de junio de 1722 ". Si este Pedro M uñoz es el mismo de la carta de examen, zcómo explicar la coincidencia de fechas?

D esde I570, las ordenanzas que reglamentaban el trabajo de carpintería y albañilería de la ciudad de Puebla prohibieron a los oficiales la realización de obra antes de ser examinados como maestros, independientemente de tener un patrocinador que los quisiera admitir. Con la finalidad de proteger a los agremiados todo carpintero poblano que deseara contratar obra debía mostrar su carta de examen al alcalde y a los veedores del gremio, así como al escribano del cabildo del ayuntamiento para que ellos comprobaran su validez.7 El caso de Pedro M uñoz podría ejemplificar la relativa observancia de dichas reglas, haciendo que el documento encontrado en el ayuntamiento no sólo resulte extraordinario por anexar el dibujo de examen sino por proporcionar información de un gran artista del cual, más allá de su participación en la siIlería coral, se tiene muy escaso conocimiento. Sin embargo, también es necesario evaluar la posibilidad de que se trate de un homónimo, posiblemente de un hijo del maestro de la sillería. A continuación presento evidencia que inclina la balanza hacia la primera posibilidad.

La presencia de oficiales no examinados ejerciendo el oficio de maestros no era del todo infrecuente en Puebla. En i692, por ejemplo, Antonio Rodríguez Guzmán (maestro del arte de carpintero de lo blanco, de lo negro y ebanista) y D iego de la Sierra (maestro mayor del arte de arquitectura, alba-

7. La ordenanza número ocho poblana obligaba a que "ningún oficial así de carpintería como de albañilería en tanto que no fuere examinado en esta tierra o en los reinos de Castilla, no pueda hacer ninguna obra hasta en tanto que sea examinado y vista su habilidad si basta para poder usar cualquiera de los dichos oficios y hablar en las dichas obras, y que aunque los señores de las dichas obras le quieran admitir, al que así no fuere examinado en los reinos de C astilla o en esta tierra y quisiere hablar de la dicha obra a poner la dicha tienda, no la pueda hacer hasta tanto que haya mostrado su carta de examen, en cualquiera de las dichas facultades y mostrada al dicho alcalde y veedores y examinadores junto con el escribano de cabildo, para que se vea y compruebe si la dicha carta que así mostrare es válida para poder usar de ella". Díaz Cayeros, "Las ordenanzas... ", op. cit., pp. ıо8-ıo9. 
ñilería y cantería) denunciaron a tres oficiales. Como veedores de dos gremios que se encontraban unidos por sus ordenanzas, Antonio Rodríguez y Diego de la Sierra denunciaron penalmente al oficial albañil Cristóbal de O rtigosa y a los oficiales carpinteros Antonio de M oya y Juan de la Parra. Probablemente este C ristóbal de $\mathrm{O}$ rtigosa fuera el C ristóbal de $\mathrm{H}$ errera $\mathrm{Ca}$ macho y 0 rtigosa que aparece como veedor del oficio de albañilería en el examen de Pedro M uñoz. En ese mismo año de i692, los veedores acusaron a O rtigosa de encontrarse "trabajando y maestreando" unas casas altas y bajas de N icolás Godines en la calle que iba del Colegio del Espíritu Santo a los molinos; a Antonio de M oya por trabajar en tienda pública en la calle de Santo D omingo y a Juan de la Parra por oficiar delante del convento de religiosas de Santa Teresa, pues ambos oficiales de carpinteros trabajaban en tienda pública sin haber sido examinados ni presentado en su juzgado sus cartas de examen. Los veedores pidieron que el escribano, en compañía del ministro de ese juzgado, fuera a las casas en donde los susodichos trabajaban, los aprehendiera y llevara a la cárcel pública. En lo que respecta a C ristóbal de O rtigosa, al día siguiente estaba preso. Suplicó ser puesto en libertad por no contar con buena salud y explicó que hacía dos meses, más o menos, estaba por ir a la ciudad de M éxico a examinarse de maestro del dicho arte de arquitectura y albañilería. Dijo haber hecho las informaciones necesarias, pero que $D$ iego de la Sierra - quien ahora lo acusaba - consideró que el examen no era necesario y que los gastos eran "muy crecidos". Afirmó que el maestro le había propuesto y dado permiso de trabajar uno o dos años, y ofrecido examinarlo una vez que transcurriera ese tiempo. Con esta historia, O rtigosa solicitaba un plazo de tres meses para examinarse. ${ }^{8}$

Es posible que la muerte del patrocinador de Pedro M uñoz fuera el acontecimiento que promoviera su examen e impidiera que éste corriera una suerte similar a la de 0 rtigosa. El cronista poblano D iego Antonio Bermúdez de Castro (1692/I693-1746) narra en su historia de la ciudad de Puebla que la siIlería fue realizada dentro del palacio episcopal bajo la dirección y el influjo del obispo don Pedro N ogales D ávila. ${ }^{9}$ El 9 de julio de ${ }_{172 I}$ fallecía el prelado y con él se vulneraba la situación en la que el artesano había estado traba-

8. Archivo M unicipal de Puebla, Expedientes (serie 3 ), volumen 222, fs. 432-439. Sigo la paginación moderna del volumen.

9. Diego Antonio Bermúdez de C astro, Theatro angelopolitano, Puebla, Junta de M ejoramiento M oral, Cívico y M aterial del M unicipio de Puebla, 1985, p. 206. 
156

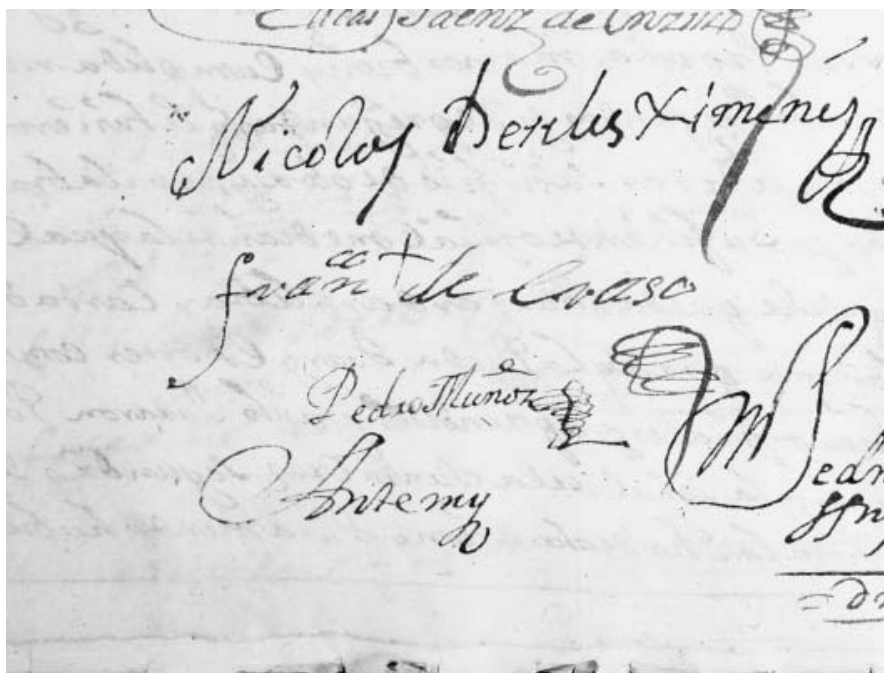

2a. Firma de Pedro M uñoz, Archivo M unicipal de Puebla, Expedientes (serie 3 ), volumen 220, f. I55V. Foto: Patricia Díaz Cayeros.

jando en los últimos dos años: bajo la protección de un patrocinador poderoso y dentro de un espacio que no era público. En mi opinión, este factor explica el que menos de un mes después el artesano recibiera de las autoridades del gremio de carpinteros de Puebla y del ayuntamiento el título de maestro en los ramos de ebanistería y carpintería de lo blanco, pero es necesario hacer ciertas precisiones. En los inventarios y avalúos que se realizaron de los bienes del difunto obispo durante el mes de julio, Pedro M uñoz aparece como maestro carpintero y los trazos de su firma coinciden con los de las firmas que posteriormente aparecen en los exámenes. ${ }^{\text {IO }} D$ e especial interés es un documento de los Expolios con fecha del 2i de julio de i72I. En éste, Pedro M uñoz acepta ser nombrado valuador y jura hacerlo sin cometer fraude. D espués de la firma del maestro, se registra la firma de un hombre que fungió como testigo y que también respondía al nombre de Pedro M uñoz. Al confrontar ambas firmas con las que aparecen en los exámenes pude constatar que la que coincide con los exámenes es la que corresponde al maestro 


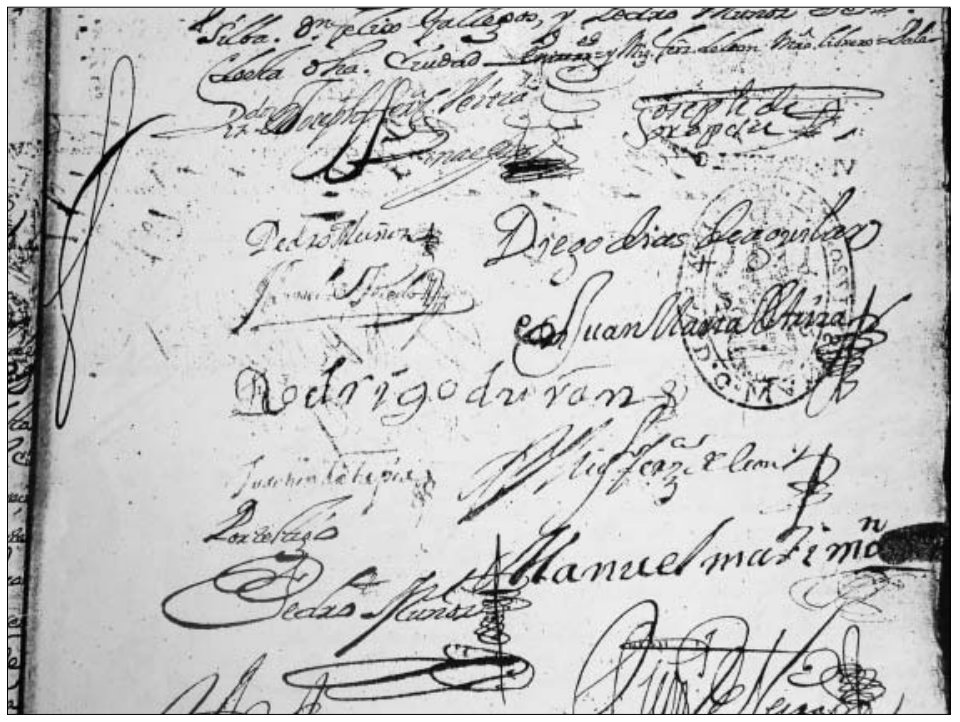

2b. Firma de Pedro M uñoz, Archivo G eneral de la N ación, Expolios, t. I5, exp. I, I72I, f. 28.

carpintero y no la del testigo. ${ }^{\text {II }} \mathrm{Si}$ el carpintero de la sillería de coro, el maestro que realizó el avalúo de los bienes del obispo y quien se examinó en los ramos de carpintería de lo blanco y ebanistería son la misma persona, ¿cómo explicar el interés de Pedro Muñoz en examinarse de nuevo?

Las ordenanzas del gremio explican que los carpinteros podían examinarse en varios niveles y aun pudiendo tener tienda se les prohibía usar el oficio o tomar obras que sobrepasaran o excedieran la facultad para la cual habían sido examinados. ${ }^{12}$ Como hemos visto, Pedro M uñoz ya era un maestro examinado al tiempo que trabajaba en la sillería del coro; sin embargo, es posible que se encontrara realizando una obra que sobrepasaba las facultades que avalaba su examen de maestro. Así, es posible acercarse a los exámenes rea-

II. Q ueda para un estudio posterior investigar si este testigo está o no relacionado con el constructor de la sillería. El trazo de la letras " $M$ " y "ñ" curiosamente corresponde a la manera en que el nombre fue escrito por el escribano dentro del texto que antecede. Sirva esta pista para una futura solución del problema.

I2. Véase ordenanza 6 en Díaz Cayeros, op. cit., p. ro8. 
lizados en agosto de i72i dentro del marco de las ordenanzas i4 y is que obligaban a volverse a examinar cuando el maestro se encontrara en esta situación. ${ }^{13} \mathrm{~A}$ partir de la lectura exclusiva de las ordenanzas se pudiera pensar que el nivel más bajo al cual podía aspirar un carpintero era el de ebanista (el tipo de trabajo que Pedro M uñoz se encontraría realizando en el palacio episcopal); sin embargo, como deja ver la carta de examen que el is de enero de I72I se le otorgó a M iguel G arcía, era posible examinarse tan sólo de "maestro carpintero". Los veedores del oficio de carpinteros declararon que habían examinado a M iguel García, de veintiún años, después de lo cual le dieron poder y facultad para que pudiera usar y ejercer el oficio de carpintero con tienda y obrador público. ${ }^{14}$

La evidencia presentada me inclina a pensar que la carta de examen que ahora se da a conocer corresponde al artista que realizó el extraordinario trabajo de marquetería de la sillería del coro de la Catedral de Puebla. Por lo tanto, el documento permite conocer el tipo de formación que para entonces había alcanzado el artista. Además, informa que se trató de un originario de la ciudad de Puebla ("español, vecino y natural"). Así, el documento ayuda a contextualizar la utilización tan sui generis que en la sillería poblana se hizo de modelos europeos y la afortunada coincidencia de la dirección intelectual de un obispo peninsular y la habilidad y tradición formal de un artista local.

\section{EL DOCUMENTO ${ }^{\text {IS }}$ \\ [f. I53V]}

Al margen: "Examen en 6 de agosto de I72I años."

En la muy noble y muy leal ciudad de los Ángeles a seis días del mes de agos-

13. La ordenanza i4 indicaba a los que ya estuvieran examinados de tenderos que "si en algún tiempo supiere hacer al guna obra fuera e se quisiere examinar de ello, que el dicho alcalde e examinadores le examinen". La ordenanza is indicaba que "si en algún tiempo el tal oficial que se hubiere examinado hubiere deprendido más de lo que la primera vez se examinó o quisiere tornarse a examinar de lo demás que supiere y hubiere deprendido los dichos examinadores, sean obligados a lo tornar a examinar y le dar su carta de examen de todo aquello que diere razón". Díaz Cayeros, op. cit., p. iıo.

I4. Archivo M unicipal de Puebla, Expedientes (serie 3 ), volumen 220, fS. I42V-I43. H e seguido la numeración moderna que abarca el volumen completo, marcada con lápiz.

I5. Archivo M unicipal de Puebla, Expedientes (serie 3), volumen 220, fs. $153 \mathrm{~V}$ y I55. He 
to de mil setecientos veinte y un años ante los capitanes y regidores don Ignacio Javier de Victoria Salazar y Frías, alférez mayor y alcalde ordinario por preeminencia de su oficio y ausencia del general don Joseph $\mathrm{N}$ úñez de Villavicencio que lo es en ella y don Joseph de U rosa y Barsena, alcalde provincial de la santa [f. I5s] hermandad de esta ciudad y su obispado y don Lucas Sáenz de Enciso, Justicia y Diputados Fieles Ejecutores en esta ciudad por su M ajestad y por ante mí, el escribano. Parecieron M iguel Ruiz de $\mathrm{N}$ arváez, alcalde, y N icolás de Selis, veedor del oficio de carpinteros de lo blanco y ebanista, Francisco de E raso, veedor de dicho oficio por lo que mira a la carrocería y Cristóbal de $\mathrm{H}$ errera Camacho y O rtigosa, también veedor por lo que mira a la albañilería y cantería, a quienes yo el escribano doy fe que conozco, y dijeron que en conformidad de las reales ordenanzas de dicho su oficio han examinado en él por lo que mira a el ramo de ebanista a Pedro M uñoz, español, vecino y natural de esta ciudad, a el cual el día cuatro de este presente mes y año de la fecha juraron ante sus mercedes haber examinado asimismo en el dicho oficio de carpintero por lo que mira a lo blanco y se le despachó título en forma para su uso y ejercicio, el cual es un hombre de mediano cuerpo, ojos pardos el color, adusto pelo negro corto y con entradas de calva y un lunar sobre la ceja izquierda y le mandaron trazar una puerta de capilla de escritorio que es la que está cosida en el original de esta carta y asimismo trazó un bufete, sobrepuesto una basa, una cornisa y un lazo en un ochavo y lo ejecutó por sus propias manos bien y cumplidamente y que a todas las preguntas y repreguntas que le hicieron a el caso tocantes, a todas satisfizo de obra y de palabra como hábil, capaz y suficiente oficial mediante lo cual declararon que se le puede mandar dar y librar carta de examen en forma para que le pueda usar y ejercer con tienda pública, oficiales y aprendices y así lo juraron por D ios N uestro Señor y la señal de la Santa Cruz según derecho y por sus mercedes vista la dicha declaración y juramento hubieron por [f. I55V] examinado a el dicho Pedro M uñoz en el referido oficio de carpintero por lo que mira a el ramo de ebanista y en todo lo que le toca y pertenece y le dieron poder y facultad para que lo pueda usar y ejercer con tienda pública oficiales y aprendices así en esta ciudad como en todas las demás del Rey N uestro Señor donde viviere y residiere y de parte de Su M ajes-

seguido la numeración moderna que abarca el volumen completo, marcada con lápiz. Se ha modernizado la ortografía y la puntuación. 
tad - que Dios guarde- exhortan y requieren y de la suya piden y ruegan de merced a todos sus jueces y justicias no consientan que en el uso y ejercicio de dicho oficio se le ponga embarazo ni impedimento alguno, antes le manden dar y den todo el favor y ayuda que hubiere menester para que goce de todos los honores, gracias, privilegios e inmunidades de que gozan y deben gozar los demás maestros examinados de dicho oficio a los cuales mandamos hayan y tengan al dicho Pedro M uñoz por maestro examinado y como a tal le citen y llamen a todas sus juntas, cabildos y elecciones y que para título se le dé un tanto de esta carta sellado su traslado con el sello de esta N obilísima Ciudad y refrendado de mí el escribano en el cual sus mercedes dijeron interponían e interpusieron su autoridad y judicial decreto tanto cuanto pueden y ha lugar en derecho y le firmaron con dichos maestros examinadores y el examinado que asimismo juró guardar el tenor de las reales ordenanzas, siendo testigos Gregorio de M endizábal, Joseph de León y M artín de $\mathrm{H}$ errera, vecinos de esta ciudad.

[Firman] Joseph de U rosa Barsena Laynes, M iguel Ruiz de Narváez, Lucas Sáenz de Enciso, N icolás de Selis Jiménez, Cristóbal de H errera Camacho y O rtigosa, Francisco de Eraso, Pedro M uñoz, ante mí, Pedro I báñez C abellos, escribano real de cabildo.\$ 